\title{
QUEM É BEM-VINDO? A SECURITIZAÇÃO DA MIGRAÇÃO E O PAPEL DA UNIÃO EUROPEIA E DA ITÁLIA
}

\author{
Higor Hebert França da Cunha ${ }^{1}$
}

\section{RESUMO}

O objetivo deste artigo é analisar as políticas de proteção aos migrantes extracomunitários ao continente europeu em relação às políticas de fronteira e de segurança da União Europeia e dos Estados-membros. A partir do estudo da União Europeia e do caso da Itália - por meio de documentos oficiais, atos de fala e depoimentos de migrantes -, procura-se entender de que forma o posicionamento do bloco estaria tendendo aos interesses internos ou à implementação das normas de direitos humanos. Desde a Primavera Árabe e a eclosão de conflitos em diversos países - a exemplo da Líbia -, houve o aumento dos fluxos migratórios para a Europa e, em especial, para a Itália, que demonstraram as limitações e os problemas de todo um sistema político baseado no conceito da diferença. Este trabalho terá como aporte teórico principal as teorias de securitização das Relações Internacionais, onde os atos de fala serão entendidos como formadores de uma determinada realidade - que no caso deste artigo, será a restrição à mobilidade. Ademais, esta pesquisa procura questionar as visões mais tradicionais da disciplina, focando na ideia do Estado e do sistema internacional, reproduzidos como instituições fixas, atemporais e ahistóricas. Os pressupostos de nação, fronteira e identidade serão igualmente problematizados, no intuito de demonstrar como as relações sociais são fluídas, não estando limitadas a um modelo socio-político entendido como dominante. $\mathrm{O}$ migrante, securitizado por políticas de exceção e práticas de restrição à mobilidade, passa a ser rotulado como uma ameaça existencial. Com uma pesquisa conjunta dos níveis nacional e europeu, pretende-se comparar as políticas de proteção aos migrantes com o processo de integração europeu. Considerando a política comum de fronteiras - Espaço Schengen - e a Frontex (Agência Europeia de Gestão da Cooperação Operacional nas Fronteiras Externas), argumenta-se que o livre movimento dos migrantes é restringido em nome de um discurso de segurança e identidade.

Palavras-chave: União Europeia; Securitização; Migrações; Identidades; Nações.

\footnotetext{
${ }^{1}$ Mestrando em Relações Internacionais pelo Instituto de Relações Internacionais da Pontifícia Universidade Católica do Rio de Janeiro. E-mail: higorfrancacunha@gmail.com.
} 


\section{ABSTRACT}

The aim of this article is to analyze European protection policies for extra communitary migrants in relation to European Union and member-states' border and security policies. With a study of the European Union and the case of Italy - through official documents, speech acts and witness of migrants -, this paper seeks to understand whether the stance of the European Union would be tending to its internal interests or to the implementation of human rights norms. Since the Arab Spring and the outbreak of conflicts in different countries - such as Libya -, there was an increasing in migrants flows to Italy, which has shown the limits and the problems of a political system based on the concept of difference. This paper will have as its main theoretical background the approaches of the securitization theories of International Relations, where speech acts will form a certain reality - in the case presented here, it will be the restriction of mobility. Also, this research intends to debate the mainstream visions of the discipline, focusing on the idea of the state and of the international system, reproduced as fixed, atemporal and ahistorical institutions. The assumptions of nation, border and identity will be problematized as well, in the sense of demonstrating how social relations are fluid, not being limited to a socio-political model regarded as the dominant one. The migrant, securitized by politics of exception and practices of mobility restriction is, therefore, labeled as an existential threat. With a joint research of the national and European levels, this work pretends to compare migrants' protection policies to the European integration process. Considering the common borders policies - the Schengen Area - and Frontex (The European Agency for the Management of Operational Cooperation at the External Borders of the Member States of the European Union) -, it will be argued that the free movement of migrants are restricted in name of a security and identity discourse.

Keywords: European Union. Securitization. Migrations. Identities. Nations. 


\section{Introdução}

Este artigo visa entender como as políticas de proteção ao migrante extracomunitário da União Europeia e dos Estados-membros têm sido construídas em relação aos mecanismos conjuntos de administração das fronteiras externas, vide a restrição à mobilidade imposta por estes. A partir das ações tomadas pela União Europeia e do estudo de caso da Itália, será analisado como os migrantes que partem da África e do Oriente Médio figuram neste cenário, que envolve tanto o regime de direitos humanos como a agenda de segurança e de integração ${ }^{2}$ do bloco europeu.

Formada em 1992 com a assinatura do Tratado de Maastricht, a constituição da União Europeia vem de um longo processo histórico, com as primeiras instâncias organizacionais e políticas surgindo no pós Segunda Guerra Mundial (NUGENT, 2006, p. 9). Em seu cerne, está a integração e o fim das animosidades políticas entre os Estados, que por tanto tempo geraram conflitos armados e desconfiança (Idem, p.4-5). Para muitos, ou a Europa seguiria um modelo de integração que permitiria um continente pacífico, ou os governos estariam no caminho da fragmentação da região que, em última instância, conduziria ao seu fim (WÆVER, 1996, p.123-124).

Entre os diversos assuntos debatidos no âmbito europeu, a agenda da migração é uma temática chave no bloco. Desde os anos 1980, esta passa a fazer parte das políticas de segurança europeias, onde há o início da construção da imagem do migrante como ameaça (HUYSMANS, 2000, p.755). O tema da migração tem relação direta com as fronteiras e os mecanismos de controle criados pelos Estados e pela União Europeia, uma vez que estes passam a cooperar cada vez mais para restringir a entrada dos chamados "imigrantes ilegais" e, por meio de práticas securitizadoras, retiram-nos os direitos de refúgio e proteção ${ }^{3}$.

${ }^{2}$ A integração europeia será entendida neste artigo como a união dos Estados europeus em um mecanismo de partilha de soberania, fruto de um projeto de longo prazo que tem como fim maior a estabilidade do continente (WFVER,1996).

${ }^{3} \mathrm{O}$ processo de europeização, que vem a partir dos anos 1980 , precisava criar a ideia de "Europa" enquanto unidade, onde as identidades nacionais - que passam a estar ameaçadas - tornam-se parte da agenda de segurança. Com a construção de uma "Europa única", a transposição da diferença passa a estar fora do continente - onde o migrante extracomunitário vira a ameaça (Idem). 
Evocando discursos em nome de uma ameaça existencial, os governantes tomam medidas entendidas como "práticas de exceção" (BUZAN; WÆVER; DEWILDE, 1998). No contexto analisado, estas seriam ações que vão contra o direito nacional e os princípios constitutivos da União Europeia, legitimadas em nome da proteção do cidadão nacional sobre a ameaça do outro, o migrante. A partir do Acordo de Schengen ${ }^{4}$, as fronteiras internas da Europa foram abolidas ao mesmo tempo em que há a contínua fortificação das fronteiras externas. Uma vez que estas se tornam "fronteiras europeias", há o discurso da necessidade de proteger o continente da ameaça estrangeira ilegal migrante, que uma vez dentro do Espaço Schengen, poderia circular livremente (BIGO, 2009, p.580; GUILD, 2001, p.9).

Para analisar estas temáticas, este artigo terá como base as abordagens das teorias de securitização, que procuram entender como atos de fala em face de uma ameaça existencial legitimam práticas de exceção, que uma vez reproduzidas, passam de atos de emergência a ações normalizadas e legais. Relacionando com a temática deste trabalho, o migrante externo à União Europeia, entendido como o outro e visto como a ameaça passa a ser securitizado a partir destes atos de fala e processos fora do âmbito legal.

Tão discutida na academia e, em maior particularidade, nas Relações Internacionais, as visões sobre o tema da segurança apresentam uma série de ramificações e entendimentos que se permeiam, sobretudo, no debate construído entre o Estado e a sociedade. Desde o fim da Guerra Fria, é teorizado por diversos autores como a noção de segurança não é mais somente ligada ao Estado e este, por sua vez, não é mais visto como o único ator principal da política (WÆVER, 1998). No lugar, as sociedades passam a ter um papel fundamental e mesmo preponderante.

Neste sentido, o estudo da temática migratória e da mobilidade é de extrema importância quando esta se mostra uma realidade de grande força no cenário internacional, que não só desafia as estruturas políticas existentes, como traz questionamentos ao mundo "ideal” e "permanente" do Estado-nação. Como colocado por Carolina Moulin

${ }^{4}$ O Acordo, assinado em 1985, antes da criação do próprio bloco, abarca a livre circulação de bens, capital, serviços e pessoas. Entre os quatro objetivos, o último é o mais controverso, uma vez que a agenda de migração permaneceu por muito tempo sobre o seio intergovernamental da União Europeia. 
(2011), a mobilidade humana faz parte da vida de todos e vem de milênios antes da formação do Estado, mas uma vez em que o migrante é colocado em um discurso de ameaça, o movimento torna-se um problema de segurança (MOULIN, 2011, p.10-11).

Procurarei analisar o tema da migração neste trabalho relacionado à construção dos conceitos de nação, identidade e Estado, focando na formação e reprodução da fronteira como o centro da pesquisa, entendendo-a não somente pela sua demarcação geográfica que separa um Estado de outro, mas também como uma delimitação política e imaginada (RAJARAM; GRUNDY-WARR, 2007).

Igualmente importante, é preciso considerar o fenômeno dos movimentos migratórios da modernidade a partir da produção e reprodução das desigualdades internacionais e, principalmente, quando este discurso - envolvendo o termo "Terceiro Mundo" - é incluído nos atos de fala. Esta demarcação, ao mesmo tempo em que serve para o Estado como forma de divisão entre o nacional e o outro, também reforça e reflete o problema de um sistema internacional que não é homogêneo e apresenta processos desiguais de desenvolvimento compartilhado entre as pessoas (LUI, 2004, p.120-121).

Dessa forma, a pergunta de pesquisa levantada neste trabalho é: Como a União Europeia e os Estados-membros estão construindo a sua política de proteção ao migrante em relação à sua política de segurança e controle de fronteiras ${ }^{5}$ ? Visa-se avaliar se há um processo de securitização por parte dos Estados, ou se há dois movimentos em torno da securitização: um realizado pelos governos nacionais e outro pela União Europeia. O bloco será entendido como o ator que deveria resguardar os valores dos direitos humanos, mas que em meio a um ambiente de crises, acaba muitas vezes por silenciar, ou mesmo, apoiar e ratificar as ações securitizadoras dos Estados.

Será defendido neste artigo que a política migratória no âmbito nacional e da União Europeia cria políticas securitizadoras que tencionam os princípios constitutivos da própria organização. Os Estados-membros e a União Europeia, por meio de uma administração conjunta das fronteiras com a Agência Europeia de Gestão da Cooperação Operacional nas Fronteiras Externas (Frontex) e com o

${ }^{5}$ Destaque dado pelo autor.

Revista Ambivalências • ISSN 2318-3888• V2 • N.4 • p. 189 - $213 \bullet$ Jul-Dez/2014. 
Acordo de Schengen, formam uma série de medidas, mecanismos e operações que têm como objetivo final limitar e dificultar a mobilidade daqueles que fogem em busca de seus direitos de proteção e mobilidade.

Ao mesmo tempo em que existe a projeção de um discurso humanitário e de promoção de regimes democráticos por parte do bloco, há uma prática dual deste, pois ao considerar o movimento como uma questão de segurança, criam-se ações na direção do controle e da vigilância. A União Europeia, neste trabalho analisada pelas decisões da Comissão Europeia, principalmente, na necessidade de manter o cerne da integração do continente, acaba muitas vezes permitindo e apoiando práticas que criminalizam as migrações e não mantendo as suas normas de proteção e direitos humanos. Dessa forma, será pesquisado como essa dualidade é construída e refletida na prática, bem como a sua efetividade.

Conjuntamente, também será discutido se há um vácuo de responsabilidade entre os Estados e a União Europeia sobre quem tem o verdadeiro dever da proteção daqueles que migram e buscam proteção. Uma vez que se criminaliza o movimento e existe um foco em políticas para impedir a entrada destes em solo europeu, o continente estaria passando hoje por uma crise legal e ética do seu verdadeiro papel de promotora dos direitos humanos.

$\mathrm{O}$ artigo, primeiramente, discutirá as teorias de securitização e as abordagens mais críticas das Relações Internacionais, argumentando como estas podem oferecer alternativas as visões do chamado mainstream da área e desconstruir a imagem do migrante como um problema. Após, será analisado como o processo de integração da Europa e as insurgências políticas no Norte da África e no Oriente Médio configuram em um cenário de criminalização do movimento, onde prevalece um discurso de segurança que reforça a diferença entre quem tem direito a direitos e quem deve ser banido. E assim, este trabalho também procurará trazer novas perspectivas sobre as formas de se entender um mundo demarcado em fronteiras, que como será expandido aqui, é muito mais complexo e plural do que uma divisão criada em nações e países. 


\section{Os processos de securitização na Europa: quem é bem-vindo?}

Falar sobre as migrações nas Relações Internacionais é escrever acerca da mobilidade, do ir e vir e do direito ao movimento. Entretanto, quando procuramos entender a temática migratória a partir do mundo ao qual vivemos - o mundo estatal - , percebe-se que existem dinâmicas e práticas que permeiam e limitam a mobilidade a partir da ideia de nacionalidade entre um eu e um outro. Como colocado pela autora Heather Rae (2002), o sistema internacional de Estados soberanos baseado em territórios nacionais é fundado no problema da diferença (RAE, 2002, p.4).

Heather Rae, no livro State Identities and the Homogenization of Peoples, descreve o que chama de homogeneização patológica, um processo de formação da diferença que envolve tanto o espaço territorial quanto o meio social vide um outro. $\mathrm{Na}$ necessidade de formar um Estado e um sistema, mantendo-os homogêneos, um discurso de ameaça pode ser exaltado, visando reforçar a existência deste espaço sobre outros indivíduos. Por serem diferentes e ameaçarem a sua unidade, são entendidos como aqueles que podem ser colocados para fora e eliminados por não pertencerem ao seu espaço (RAE, 2002, p.4-5).

Ole Wæver, ao trabalhar com o conceito de identidade no contexto europeu, afirma que é o compartilhamento de características comuns que fazem o 'nós' existente, criando-se um sentimento comum de pertencimento de um mesmo local (WÆVER, 1993, p.18). A formação das sociedades segue um longo processo de organização política, sendo hoje pensada na figura do Estado, caracterizado por uma nação, um território e definido pela fronteira. O Estado, que para alguns autores é o símbolo da modernidade e o único ator da política é, para muitos teóricos, uma construção social que se desenvolveu no tempo e no espaço - mas que foi fixada na história por um discurso político e teórico estabelecido.

Segundo Robert Walker (1993), foi colocado pela disciplina de Relações Internacionais - em especial, pelas teorias racionalistas - que as noções de territorialidade, fronteira e soberania são, a priori, entendidas como o único modelo político-social existente (WALKER, 1993, p. 4-5). Walker afirma que o discurso dominante na disciplina toma a formação do Estado e o seu momento histórico como um 
período temporal único, tornando outras formas de organizações políticas impensáveis (Idem, p.7). Entretanto, com o passar do tempo, entendeu-se que o Estado era apenas um modo de se ver um mundo em constante transformação, passando-se a pensar que outras formas de se reorganizar o espaço político podem ser imaginadas - e que já podem estar ocorrendo.

Assim, a noção de Estado, vista como a essência das Relações Internacionais, passa a ser questionada. Em períodos de mudanças e transformações, com os novos movimentos transnacionais e os processos migratórios cada vez maiores, estes passam a se impor sobre a centralidade deste ator (Idem, p.13). Ao mesmo tempo, há a contínua necessidade de manter viva a ideia do "Estado" - e como trabalhado neste artigo, da União Europeia - como ator necessário e que proteja a sua sociedade. Por meio de estratégias e práticas que evoquem a defesa da sua permanência, discursos são produzidos no intuito de mantê-lo vivo e de defender a sua unidade. Será trabalhado neste artigo como os atos de fala são formadores de práticas de exceção, a partir do processo de securitização (BIGO, 2002; BUZAN; WÆVER; DEWILDE, 1998).

A ideia de securitização foi sistematizada em 1998 por Ole Wæver, Barry Buzan e Jaap de Wilde no livro Security: A New Framework For Analysis. Os três autores procuraram analisar como uma ameaça é construída de determinada forma e como ela pode ser estabelecida e legitimada. No segundo capítulo do livro é colocado como o processo de securitização parte de temas despolitizados que viram politizados e, alguns, securitizados. Uma vez rotulados desta maneira, clamam por ações emergenciais vide uma ameaça existencial que coloca a audiência em perigo (BUZAN; WÆVER; DE WILDE,1998, p.23-24).

Para os autores, o significado de um conceito parte do uso do que é feito com ele, onde uma questão que até então não era vista como uma agenda de segurança passa a ser um problema (idem, p.25). Neste sentido, a securitização"[...] is constituted by the intersubjective establishment of an existential threat with a saliency sufficient to have substantial political effects" (idem). Ela é construída por meio de atos de fala e constelações políticas em que se consegue, via um argumento, o apoio da audiência para implementar ações fora do âmbito das leis e dos procedimentos. É importante supracitar que a securitização só é possível com o apoio da audiência - o público -, pois caso contrário, há apenas o movimento securitizador (idem). 
No artigo European Security Identities, Wæver analisa o conceito de segurança societal dentro da Europa, entendendo segurança como sobrevivência (WÆVER, 1996, p.107). Uma vez que um tema é apresentado como ameaça existencial, a partir da ideia socialmente aceita de que o ameaçado deve sobreviver, necessita-se de uma ação devido ao seu caráter emergencial (ide.). O caminho da integração da Europa levou a uma transposição do outro que até então se encontrava dentro do continente, no intuito de criar um sentimento comum de união.

A identidade e a segurança societal são entendidas na conjuntura de um mundo com novas vulnerabilidades, respondendo ao papel da União Europeia enquanto órgão regional, que também afirma uma ideia de que o Estado já não é mais o único objeto referente (Idem, p.122-123). Em uma realidade de mudanças, as identidades locais passam a ser entendidas como vulneráveis, e sem a sua proteção, tornam-se uma pauta de segurança. Sua existência enquanto identidade deve diferenciar-se de um outro, que vem de fora das fronteiras da Europa que ameaça e que coloca em risco as identidades existentes (Idem, p.126-127).

Lidando especificamente com a temática migratória, Didier Bigo (2002) entende a securitização da migração como "a transversal political technology, used as a mode of governmentality by diverse institutions to play with the unease, or to encourage it if does not yet exist, so as to affirm their failures" (BIGO, 2002, p.65). Bigo trabalha com a ideia da governamentalidade do receio, em que o autor procura entender o motivo da permanência dos discursos sobre a securitização da temática. Bigo argumenta que tal processo ocorre devido aos interesses que as novas tecnologias de controle e vigilância trazem, e aos políticos também, na sua autoridade e poder (simbólico) sobre o território (idem, p.64-65).

Ao mesmo tempo, Didier Bigo tem uma fundamentação diferente de Buzan, Wæver e de Wilde. Bigo acredita que os autores, ao trabalharem com a noção da securitização acima da política, acabam mesmo que de forma não intencional - ratificando a visão de que “security is an 'explanation' of the security process and not a discourse to be challenged" (Idem, p.73), e também, com os mecanismos coercitivos como a solução para lidar com a exceção (Idem, p.74). Para Bigo, a securitização funciona por meio das tecnologias do dia a dia e 
de um poder que não faz parte de uma exceção, mas, ao contrário, é ininterrupto, que vive pelos interesses e lutas políticas pelos profissionais de segurança (Idem, p.73).

Assim, é entendido como o migrante é visto como uma ameaça, pois primeiro é demarcado como um alvo para as tecnologias de controle e vigilância, sendo somente depois visto como uma ameaça à fronteira (Idem, p.77). O próprio rótulo imigrante ${ }^{6}$ é uma forma de se criar uma imagem negativa deste, rotulando-o como cidadão do "Terceiro Mundo", diferente dos europeus - entendidos como um 'corpo homogêneo', segundo Bigo (Idem, p.80).

Seguindo sua análise, em Detention of Foreigners, States of Exception, and the Social Practices of Control of the Banopticon, Bigo pesquisa a diferenciação entre os discursos e os permanentes casos de emergência (BIGO, 2007, p.4). Argumentando que os controles nas fronteiras da União Europeia sobre os migrantes são uma forma de banopticon da governamentalidade, afirma que há uma "normalização" das práticas de detenção e repatriação (Idem, p.4-5). O banopticon, relacionado à ideia do panopticon, do filósofo Jeremy Bentham, lida com a noção de exceção e a diferença entre vigilância para todos e o controle para alguns (Idem, p.6). Há um exercício de banir aqueles que são entendidos como o perigo, em um momento onde a fronteira está em cheque, trazendo o medo do incerto e da ameaça que agora pode cruzála rumo ao inside (Idem, p.10-12).

No banopticon, a arbitrariedade passa a ser a norma e não a exceção a rotina da exceção, propriamente dita (Idem, p.13). Didier Bigo, a partir da análise de uma Möbius ribbon (fita de Moebius) - figura geométrica que não contém um dentro e um fora, mas é uma continuação, sem uma definição clara de espaço e de começo e fim -, transporta este princípio à análise da securitização da migração (BIGO, 2002, p.76). Entendendo que se procura banir a ameaça, não há uma definição clara entre quem é o outsider e o insider, pois o migrante é visto como alguém que não faz parte do sistema, mas é entendido

${ }^{6}$ Por este motivo, este artigo procurou utilizar-se da categoria migrante e não, imigrante ou emigrante. Uma vez que a diferenciação entre aqueles que vêm de fora e os que estão no território demarca o acesso - ou a falta - de direito a direitos, procura-se neste trabalho não reproduzir as mesmas desigualdades encontradas nos documentos e discursos oficiais. 
como um problema que deve ser erradicado, classificado como o 'estranho'.

Permanecendo em um limbo, ações fora do cunho legal existente são "permitidas", legitimando, por exemplo, os atuais campos de detenção financiados pela Europa para migrantes e a própria constituição da Frontex. Não havendo uma definição entre quem deve proteger e quem deve atuar e responder - tanto Estado quanto União Europeia -, é possível que se opere na margem, no interesse de expulsar este double outsider do território e da modernidade (WALKER, 2006).

\section{A restrição à mobilidade e a externalização do controle}

The boat had departed from Libya and the passengers were trying to escape the ongoing conflict and reach Europe. However, they quickly ran out of fuel and of their meagre supply of water and food. People on the boat made desperate calls using a satellite phone alerting an Eritrean priest in Rome to their predicament. He in turn contacted both the Italian Coast Guard and NATO headquarters in Naples. According to survivors, a military helicopter lowered some water and biscuits with a rope but never returned. Fishing boats and military vessels also reportedly approached or saw the stranded boat, but nobody rescued them. After a week, people started dying; the dead bodies were lowered into the sea. By then, those still alive on the boat had become delirious. In despair, some people jumped overboard. Eventually, the boat drifted back to Libya. Only nine of the $\mathbf{7 2}$ people survived this horrific journey $^{7}($ AMNESTY INTERNATIONAL, 2012, p.12).

Uma vez que o migrante é entendido como ameaça e a sua presença na Europa é vista como vulnerável, o controle da mobilidade é externalizado com o objetivo de restringi-la e dificultá-la. Por meio de mecanismos que procuram minar as migrações - antes mesmo que elas aconteçam -, o direito básico de todo o indivíduo ao movimento e à proteção já lhe é previamente negado.

\footnotetext{
${ }^{7}$ Idem
} 
Entre os mecanismos para o controle das fronteiras europeias, analisarei a Frontex, criada pela Resolução 2007/2004 do Conselho de Ministros da União Europeia. Diferentemente de Schengen - que procura integrar a Europa internamente e promover a migração dos cidadãos europeus dos Estados-membros -, a Frontex não se refere a uma fronteira única e comum do continente. A agência foi criada com o intuito de monitorar as fronteiras nacionais e protegê-las, a partir de uma coordenação entre os Estados-membros e cooperação em diversas áreas, como descrito no capítulo 2 da Resolução.

A ideia de território na Frontex é baseada no viés territorial-soberano do Estado-nação - e não pela ideia de Europa criada pelo bloco (BIGO; GUILD 2010, p.14-15). A Frontex, que surge após o Tratado de Amsterdã - quando as temáticas de migração e asilo são transportadas do então pilar intergovernamental ${ }^{9}$ do bloco para o primeiro pilar -, permaneceu sobre o seio dos Estados. E a sua formação, antes de tudo, é uma medida estatal, com as suas funções estabelecidas no Artigo 2: "assist Member States on training of national border guards, including the establishment of common training standarts"; "provide Member States with the necessary support in organising joint return operations".

Didier Bigo (2002), analisando os mecanismos de vigilância na Europa e o seu papel na construção da securitização da migração, entende que as tecnologias de controle têm um forte papel no processo de securitização e na definição de uma ameaça existencial (BIGO, 2002, p.64). Enquanto alguns têm sua liberdade de movimento garantida e até, fomentada - como a criada pelo Espaço Schengen -, outros têm a sua mobilidade restringida.

Neste sentido, o contínuo processo de vigilância leva a uma normalidade do controle e de práticas de exceção que são aplicadas contras aqueles entendidos como o risco (Idem,13). Deve-se lembrar em: 07 de nov. de 2014.

${ }^{9}$ A criação da União Europeia, com o Tratado de Maastricht, foi estabelecida sobre três pilares, que seguiriam um modelo sui generis (por meio do caráter supranacional), com base em um pedestal de valores comuns.O primeiro correspondia às Comunidades Europeias, o segundoa Política Externa e de Segurança Comum (PESC) e o terceiro a Justiça e Assuntos Internos (JAI), os dois últimos sobre o pilar intergovernamental (PHINNEMORE, 2010, p.36). 
de que este é um processo que também conta com os interesses e estratégias de políticos nacionais, que reforçam estas práticas contra aqueles que procuram apenas concretizar um direito básico - o da mobilidade (Idem, p.72-73, p. 75).

A fronteira, base da raiz que define e separa a Europa, protegida e mantida por meio de resoluções e códigos e vista como o ideal de um continente unido, é a mesma que separa pessoas por região, nacionalidade e que admite indivíduos à deriva no Mar Mediterrâneo. De acordo com Meng-Hsuan Chou (2009), a agenda do controle externo esteve em sua maioria nas mãos dos ministros do interior, que entendem a migração e o asilo a partir de uma perspectiva da segurança (CHOU, 2009, p.544) - o que já demarca uma separação na vigilância da mobilidade na Europa, definida, principalmente, a partir das decisões dos Estados nacionais.

Como ressaltado por Didier Bigo e Elspeth Guild (2010), que nomeiam estas práticas de remote control, é preciso contestar os ideais e as ordens construídas com base nas fronteiras, identidades e pertencimento (BIGO; GUILD, 2010, p.3). Estas não só nos diferenciam entre o eu e o outro, mas colocam o indivíduo em patamares diferentes que criam as desigualdades aqui analisadas. O cidadão europeu, por ter nascido em um dos países membros da União Europeia e por estar em um território diferente de um indivíduo nacional de um país terceiro, é detentor de uma série de direitos, que este na condição de migrante, não o tem.

Este processo desigual, não só cria uma diferenciação para o migrante, como legitima que a sua mobilidade e a sua proteção lhe sejam negadas, vide uma estrutura baseada no território fronteirizado da nação. Como colocado por Robert Walker (2006), o projeto da modernidade, formalizado no Estado-nação, demarca uma exclusão construída do double outside, que não é parte constituinte nem do sistema internacional e nem do Estado. O migrante, na sua condição de nacional de um Estado-terceiro, vive em meio a um limbo estrutural, pois enquanto indivíduo, não pode ser encaixado em tal sistema - o que traz questionamentos sobre o próprio espaço ao qual vivemos.

Neste sentido, a autora Meng-Hsuan Chou também ressalta outro aspecto, que é sua dualidade entre a repressão e o progresso, afirmando que é o caráter repressivo que se sobressai neste quadro de controle, no 
propósito de se alcançar a segurança interna e externa (CHOU, 2009, p.543). Para Chou, a consolidação da migração e do asilo na política de segurança da Europa não deve ser entendida como intencional ao projeto de construção da União Europeia, mas resultado da resposta dos políticos nacionais às pressões internas e externas do que é entendido como ameaça (Idem, p.542-543).

Uma vez que as decisões relacionadas à externalização da segurança não incluem diretamente os dois órgãos supranacionais (Comissão Europeia e o Parlamento Europeu) mais importantes da União Europeia - e principalmente, a Comissão -, percebe-se que há um claro interesse de manter esta agenda no âmbito intergovernamental, para que não existam influências externas a dos interesses nacionais. Por outro lado, em que medida o interesse da União Europeia seria tão diferente? O bloco tomaria um posicionamento mais humanitário e voltado para o cumprimento do direito ou reforçaria as decisões dos Estados-membros?

\subsection{A Frontex e os controles migratórios na Itália: Onde está a União Europeia?}

A Frontex, como já mencionada, funciona a partir de uma coordenação dos Estados-membros. A Itália, que se encontra aos pés do mar Mediterrâneo, é um dos países mais visados da Europa nas migrações nesta região. Uma das principais rotas é o trecho entre a Líbia e a Itália, que desde os movimentos revolucionários da Primavera Árabe, vem apresentando um aumento significativo no número de pessoas que chegam ao país (NASCIMBENE; DI PASCALE, 2011; AMNESTY INTERNATIONAL, 2012).

Devido à proximidade - menor do que 300 quilômetros -, a maioria dos migrantes partem para a Itália rumo a destinos como a Sicília e a ilha de Lampedusa, no sul do país. Sendo a Itália um país membro da União Europeia, a Frontex passa a ser um forte instrumento para auxiliá-la no combate à 'imigração ilegal', com os seus governantes evocando discursos em nome desta coordenação conjunta.

Anualmente, a Frontex redige um relatório denominado Risk Analysis, que apresenta uma série de dados sobre o número de vistos 
concedidos, detenções, nacionalidade de migrantes, solicitantes de refúgio e rotas utilizadas. O relatório de 2013 demarca que a região do Mediterrâneo alcançou o patamar de 10.379 detenções em 2012 e 59.002 em 2011, tendo em vista que a grande maioria destes migrantes partiu de território líbio (FRONTEX, 2013, p.19-21). As três principais nacionalidades, em ordem decrescente, são dos seguintes países: Somália, Tunísia e Eritreia.

A Líbia funciona como uma das principais rotas de passagem para os migrantes de países terceiros que desejam chegar à Europa. Entretanto, o país não é signatário da Convenção de Refugiados de 1951 e do Protocolo Adicional de 1967, bem como também recebe diversas críticas por não aplicar as normas de direitos humanos durante o governo de Muammar al-Gaddafi (AMNESTY INTERNATIONAL, 2012, p. 5-6).

Desde 2007, a Itália mantém acordos com a Líbia relacionados à migração, com o financiamento de bilhões de euros aos cofres líbios em troca da detenção e controle de migrantes. Em dezembro de 2007, foi assinado o primeiro acordo e, em 2009, um Protocolo Adicional que se refere a patrulhas conjuntas, treinamento de guardas líbios e criação de um sistema compartilhado de informações (NASCIMBENE; DI PASCALE, 2011, p.342). Como também colocado pela organização não-governamental Anistia Internacional (2012), no relatório S.O.S. Europe: Human Rights and Migration Control, em nenhum momento os acordos citavam a proteção de migrantes ou o respeito aos direitos humanos.

Parte do financiamento da Itália teve como destino a construção de centros de detenção na Líbia, com o fortalecimento do controle no território para fluxos em massa à Itália, em um processo de externalização do controle. Em 2010, foi assinado um terceiro acordo, Technical-Operational Protocol to combat illegal migration through the sea (Idem). Entre os métodos de controle a serem analisados e, referindo-se especialmente a este tratado, estão os chamados pushbacks no mar Mediterrâneo - ações que consistem em mandar de volta para águas internacionais barcos com migrantes que se encontrem em território europeu. Estas práticas vêm ocasionando dezenas de mortes na região e trazendo a tona o problema da falta de um sistema de proteção e sinalizando as próprias falhas da estrutura do sistema de Estados baseada na fronteira e na diferença. 
Situações como estas ocorrem na Itália desde 2009 (AMNESTY INTERNATIONAL, 2012) e fazem com que barcos à deriva - muitos com jovens e crianças - levem a cada vez mais mortes, em consequência da falta de água potável, comida e insolação e, principalmente, da falta de assistência do continente europeu. Mesmo entre aqueles que sobrevivem, acabam sendo detidos e sofrendo violações nos centros (Idem, p.14). Do ponto de vista legal, há uma série de obrigações, desde a Convenção de 1951 as próprias normas da União Europeia de direitos humanos e do direito internacional marítimo. Sobre estas ações, o então primeiro-ministro italiano, Silvio Berlusconi, declarou:

On these boats, as the statistics say, people who have the right of asylum there is practically none. There are only few exceptional cases [...] For those who ask for asylum in Italy, there are laws that require us to give: to give asylum to those who come from countries where there are no freedom or there wereno police. However, we have always a humanitarian spirit [...] the left wants the doors of our country opening to all, even to illegal immigrants [...] but we believe that the doors should be closed or narrowed only to those who come to Italy to work $[\ldots]^{10}$ (LA REPUBBLICA, 2009).

E também dito pelo ministro de justiça, Angelino Alfano:

With Libya, the Italian executive has made an agreement that is fulfilling. Tripoli is our partner and we concluded a major agreement with this North African country that has to give the results. One of the results that we expect is to stop immigration from Libya - said the minister - and to plan to adopt policies without resulting in a violation of any International $\mathrm{Law}^{11}$ (Idem).

Entretanto, uma vez que há a noção de uma ameaça, medidas que se sobrepõem às leis europeias e internacionais são legitimadas. Em 2009, o governo italiano solicitou à União Europeia que a Frontex se tornasse uma agência operacional, para controlar as fronteiras e assistir nos centros de detenção ${ }^{12}$. Em 2011, com o início do conflito na Líbia, houve o fim do controle de fronteiras e a suspensão dos acordos até

\footnotetext{
${ }^{10}$ Trecho traduzido pelo autor.

${ }^{11}$ Idem

${ }^{12}$ Carta conjunta do presidente da França, Nicolas Sarkozy, e do primeiro-ministro italiano, Silvio Berlusconi, com um pedido de reformulação da Frontex, disponível em: <http://www.ambafrance-uk.org/President-Sarkozy-and-Italian〉. Acesso em: 06 de dez. 2013.
} 
então estabelecidos com a Itália, levando ao aumento expressivo do fluxo de migrantes - muitos, até então, detidos - à Itália.

Com o crescente número de migrantes entrando em seu território, Roma pediu auxílio à União Europeia, que criou uma missão da Frontex para auxiliar o país, denominada Hermes, apenas quatro dias após o apelo italiano. Uma resposta da Comissão Europeia ao caso apoia a Itália, ao mesmo tempo em que coloca o seu discurso pautado na defesa dos princípios humanitários:

The massive displacement of populations from several North African countries has been putting the protection and reception systems of some of the EU Member States, in particular in Italy and Malta, under increasing strain. The European Union has responded to these serious challenges in a rapid and effective manner with the aim of stabilizing the situation. [...] Frontex stands ready to continue the mission as long as it will be necessary, and to expand it, provided that Member States will make available the necessary staff, vessels and equipment. In view of the above the Commission is launching the necessary procedures for reinforcing the Frontex 2011 budget with an additional EUR 30million (COMMISSION EUROPÉENNE, 2011).

No mesmo documento, na seção denominada "Reinforcing Frontex", a Comissão afirma que:

Frontex should speed up negotiations to conclude working arrangements with the countries of origin and transit of irregular migration ${ }^{13}$ in the Mediterranean in the region (for example, with Egypt, Morocco and Turkey), and receive a mandate to negotiate similar working arrangements with other relevant countries (for instance Tunisia) (Idem).

Dois anos antes, a Comissão lançou um comunicado a respeito do futuro da área de Justiça e Assuntos Internos, com a afirmação do presidente da Comissão, José Manuel Barroso ${ }^{14}$ :

In future, EU action must aim above all at delivering the best possible service to the citizen in an area of freedom, security and justice more tangible for the citizens [...] We want to promote citizens' rights, make their daily lives easier and

\footnotetext{
${ }^{13}$ Destaque dado pelo autor.

${ }^{14}$ Disponível em: <http://europa.eu/rapid/press-release_IP-09-894_en.htm>. Acesso em: 06 de dez. 2013.
} 
provide protection, and this calls for effective and responsible European action in these areas. In this context, I consider immigration policy particularly important ${ }^{15}[\ldots]$ (COMMISSION EUROPÉENNE, 2009).

Na época, o então Comissário para Justiça, Liberdade e Segurança (hoje Justiça, Direitos Fundamentais e Cidadania), comissário Jacques Barrot, declarou:

[...] respect for the person and human dignity are core values of the area of freedom, security and justice. The individual should be at the heart of its construction and all future developments. Solidarity must be the watchword of the future programme. Solidarity between people, particularly the most vulnerable members of society, solidarity between Member States to find common solutions to common threats like terrorism and organised crime, to derive common benefits from the opportunities that regulated immigration, tailored to the needs of the labour market ${ }^{16}$, can create, solidarity to respond collectively to the need for protection expressed by those who seek asylum at our frontiers (Idem).

As afirmações mostram uma atuação dúbia da Comissão. Ao mesmo tempo em que há o reforço da ideia do europeu na defesa do espaço comum, onde o órgão diz que dará os direitos ao asilo e ao refúgio; na fala de Jacques Barrot, percebe-se claramente como o discurso da boa migração está ligado à ideia de trabalho e economia, ou seja, o direito será focado àqueles migrantes quem sejam interessantes à Europa - e que serão bem-vindos. Há uma divisão não só na importância entre o europeu e o migrante, como também uma sobreposição entre a própria ideia de qual migrante é o melhor para o bloco. Este pensamento, formalizado nos atos de fala dos políticos, fixa uma separação entre os indivíduos que são materialmente importantes ao continente, sem levar em consideração as suas necessidades e direitos.

Em 2010, dando continuidade às mudanças na área da segurança, a Comissão Europeia fez propostas de alterações específicas à Frontex, atendendo ao pedido dos Estados-membros que pediam por um papel mais ativo da agência. Entre os objetivos, observa-se: "Frontex will continue to be able to coordinate joint operations, returning immigrants to their country of origin. Safeguards are put in place to make sure that

\footnotetext{
${ }^{15}$ Destaque dado pelo autor.

${ }^{16}$ Destaque dado pelo autor.
} 
these return operations are carried out in full respect of fundamental rights" (COMISSION EUROPÉENNE, 2010). E como dito por Cecilia Malmström, Comissária de Assuntos Internos:

Today's proposal will pave the way for more solidarity and better cooperation between EU countries. This will give us the opportunity to better deal with irregular immigration and human trafficking, while at the same time strengthening the safeguards to guarantee full respect of fundamental rights. I hope that the European Parliament and Council will move quickly to turn this proposal into law, so that the Agency can get the human and technical resources that it needs (Idem).

Um ano depois, em 2011, a Frontex lançou uma estratégia de direitos fundamentais, que consta com diretrizes que visam pautar as suas operações em conformidade com as normas internacionais de proteção e direitos humanos. Afirma-se no preâmbulo:

Frontex aims to prevent possible violations of fundamental rights during its operations by, on one hand, developing the requisite knowledge and skills of participating officers and, on the other, implementing proper monitoring mechanisms based on reporting to the competent authorities and sanctioning, applying a zero tolerance policy (FRONTEX, 2011).

Nesta seção, a agência não só reforça que violações podem ocorrer, como também mantém a sua estrutura - um órgão de restrição ao movimento. Também é apresentado que a Frontex se compromete a agir em caso de violações. Mas quem tomaria tais decisões? O artigo 15 coloca:

Furthermore, in cases of fundamental rights breach in an operation, possibility is given to all partners involved in the operation, possibility is given to all partners involved in the operation to request the host Member State, Frontex or other Member State concerned to take immediate and appropriate measures (Idem).

O artigo não define quem tomaria as decisões, o que traz um vácuo legal na área de proteção. Além disso, quando se diz que a Frontex poderia tomar medidas necessárias, uma pergunta a ser feita seria: que país membro das missões da Frontex teria o poder de decisão? Visto que a agência é um mecanismo de coordenação entre os Estados- 
membros para vigilância das fronteiras externas, não está definido quem adotaria tais medidas imediatas.

Por exemplo, poderíamos citar as missões de vigilância marítima financiadas pelas Frontex que ocorrem em solo italiano. Uma vez que estas contam com guardas nacionais italianos e de outros países do bloco, quem seria responsável em caso de violações de normas de direitos humanos? Por mais que o documento vise ratificar a ideia de uma perspectiva humanitária dentro da agência, ele entra em contradição com o próprio objetivo da agência.

É interessante perceber o papel da Comissão neste processo. Como apontado anteriormente, a criação da Frontex veio de um interesse estatal e era fundamental para os Estados que este controle ficasse em suas mãos, uma vez que os órgãos supranacionais passavam a ter maior gerência sobre a agenda migratória (BIGO, 2009). Entretanto, com o tempo a Comissão Europeia procurou atender aos pedidos dos países, reforçando os poderes e a atuação da agência, visando, em conjunto com os Estados, combiná-las com as normas de direitos humanos - mas fazendo-a de maneira muito mais branda.

Como coloca o autor Koldo Salazar (2011), a União Europeia trabalha com padrões diferentes na política de direitos humanos, com seus dois maiores órgãos supranacionais - o Parlamento Europeu e a Comissão Europeia - tendo decisões muito mais efetivas na agenda relacionadas a países terceiros do que com os próprios Estados do bloco (p.31-32). Dessa forma, entende-se que há um duplo padrão na atuação dos órgãos supranacionais do bloco e, substancialmente, da Comissão Europeia, que deveria atuar em prol dos princípios constitutivos do bloco, mas que acaba tendendo para o lado dos Estados, uma vez que o interesse em manter o projeto europeu fortalecido e unido é maior do que a vontade de salvar vidas.

\section{Conclusão}

Durante este trabalho, procurei analisar como a política migratória do continente Europeu vem sendo desenvolvida em relação às políticas de segurança e fronteira. A categoria de migrante, debatida em extenso, passa a ser entendida mais como um rótulo para aqueles que saem de 
regiões consideradas vulneráveis e que não são os migrantes "bemvindos", em uma nomeação que já os diferencia e categoriza negativamente.A própria noção do migrante traz na discussão teórica reflexões sobre os processos de criação da diferença, fortemente baseado na ideia de pertencimento a um território definido pela fronteira. Entretanto, os conceitos aqui elucidados não devem ser entendidos como dados, mas devem ser questionados para que possam ser desconstruídos.

Os estudos sobre as migrações - cada vez mais amplos - são o reflexo de uma prática do próprio ser humano que já ocorre desde os primórdios, mas que hoje está em choque com o atual sistema político dominante. A mobilidade não vê fronteiras, mas sim diferentes espaços que não são fixos ou delimitados - e que são construídos a partir da própria formação de espaço do migrante.

Não obstante, o discurso para manter a salvo este mundo fronteirizado e, em especial, na Europa, é perigoso. Em nome da manutenção da ordem do sistema, legitimam-se práticas e ações que colocam o próprio ser humano em risco, uma vez que o direito a um território passa a ser maior que o direito à vida. No caso europeu, estas medidas são tomadas não só pelos Estados, como pelos próprios órgãos do bloco, que muitas vezes reforçam as decisões estatais.

A Comissão Europeia procura ser uma balança nas tomadas de decisões no bloco, buscando sempre manter os interesses nacionais e europeus. Na medida em que a ordem é questionada, a Comissão toma para si também os discursos de território e fronteira, deixando os seus ideais e o seu conjunto legal em segundo plano.

Principalmente, quando o migrante passa a ser entendido como a ameaça, o posicionamento do bloco é em favor do eu europeu em detrimento do migrante, de Estados terceiros. O Tratado de Schengen e a criação da Frontex marcam uma divisão da política migratória da Europa, que na busca de um continente unido, o migrante passa a ser visto como uma ameaça a esse processo de construção. Uma vez que o próprio sistema político estabelecido é formado por estruturas de exclusão, negação e violência, o migrante, na categoria de double outsider, passa a ser uma ameaça a esse sistema, que não consegue absorver as suas próprias falhas. 
Talvez esta percepção ainda não esteja clara para a Europa, mas a mobilidade e o questionamento destas fronteiras estabelecidas são fenômenos da atualidade que só ratificam os paradoxos e as dualidades deste sistema internacional e da sua própria estrutura. A resposta que o bloco oferece às migrações - uma resposta restritiva - é um reflexo da sua limitação. Ainda estamos em um espaço político que prioriza o território a uma vida, mas o direito ao movimento é procurado a cada dia por novas pessoas que entendem que tem direito à proteção e ao livre movimento, independente de onde se encontram e da sua nacionalidade.

\section{Referências}

AMNESTY INTERNATIONAL. S.O.S. Europe: Human Rightsand Migration Control. Londres: Peter Benenson House. 2012. Disponível em:

<http://www.amnesty.eu/content/assets/S_O_S_Europe_Report_Web 02.pdf >. Acessoem: 07 de dez. 2013.

BIGO, D. Security and Immigration: Toward a Critique of the Governmentality of Unease. Alternatives, 2002, p.63-92.

. Detention of Foreigners, States of Exception, and the Social

Practices of Control of the Banopticon. In: RAJARAM, P.K.; GRUNDY-WARR, C. (Eds.). Boderscapes: hidden geographies and politics at territory's edge. Minneapolis: University of Minnesota Press, 2007, p.3-33.

Immigration controls and free movement in Europe. International Review of the Red Cross, v. 91, n. 875, 2009, p.579591.

BIGO. D; ESLPETH, G. The Transformation of European Borders Controls. In: RYAN, B.; MITSILEGAS, V. Extraterritorial Immigration Control: Legal Challenges. Martinus Nijhoff, 2010, cap.9.

BUZAN, B.; WÆVER, O.; DE WILDE, J. Security: a new framework for analysis. Boulder, 1998, p.151-203. 
CHOU, M. The European Security Agenda and the 'External Dimension' of the EU Asylum and Migration Cooperation. Perspectives on European Politics and Society, v.10, n.4, 2009, p.541-559.

COMISSION EUROPÉENE. IP/09/894, de 10 de junho de 2009. European Commission outlines its vision for the area of freedom, security and justice in the next five years. Press Release Debate, Bruxelas. Disponível em: <http://europa.eu/rapid/press-release_IP-09894_en.htm>. Acesso em: 10 de nov. 2014.

IP/10/184, de 24 de fevereiro de 2010. Commission responds to calls for stronger EU border management agency. Press Release Debate, Bruxelas. Disponível em: <http://europa.eu/rapid/pressrelease_IP-10-184_en.htm?locale=fr>. Acesso em: 10 nov. 2014.

_. Memo/11/226, de 8 de abril de 2011. The EuropeanCommission's response tothemigratoryflowsfrom North Africa. Press Release Debate, Bruxelas. Disponível em:<http://europa.eu/rapid/press-release_MEMO-11-

226_en.htm?locale=fr>. Acesso em: 10 nov. 2014.

FRONTEX. Frontex Management Board, de 31 mar. 2011. Frontex Fundamental RightStrategy, Bruxelas. Disponível em: < http://frontex.europa.eu/assets/Publications/General/Frontex_Fundame ntal_Rights_Strategy.pdf>. Acesso em: 10 nov. 2014.

Annual Risk Analysis 2013. Frontex, 2013, p.1-80.

Disponível

em: <http://frontex.europa.eu/assets/Publications/Risk_Analysis/Annual_R isk_Analysis_2013.pdf>. Acesso em: 10 nov. 2014.

GUILD, E. Moving the Borders of Europe. University of Nijmegen, 2001, p.1-29.

HUYSMANS, J. The European Union and the Securitization of Migration. Journal of Common Market Studies, v38, n5, 2000, p.751-777.

LA REPUBBLICA. Firma per risarcimento Italia-Libia "Saremounitisull 'immigrazione". Roma, 2009, Cronaca. Disponível 
em: <http://www.repubblica.it/2009/05/sezioni/cronaca/immigrati7/fini-consiglio-europa/fini-consiglio-europa.html>. Acesso em: $07 \mathrm{de}$ dez. 2013.

LUI, R. The International Governments of Refugees. In: LARNER; W.; WALTERS,W. Global governmentality: Governing international spaces. London and New York, Routledge, 2004, cap. 6.

MOULIN, C. Eppur si Muove: Mobilidade Humana, Cidadania e Globalização. Contexto Internacional, v.33, n.1, 2011, p.9-17.

NASCIMBENE, B.; DI PASCALE, A. The 'Arab Spring' and the Extraordinary Influx of Migrants to Italy. European Journal of Migration and Law, v.13, 2011, p.341-360.

NUGENT, N. The Governments and Politics of the European Union. Durham NC : Duke University Press, 6ª ed, 2006, 656 p.

PHINNEMORE, D. The European Union: Establishment and Development. In: CINI, Michelle; BORRAGÁN, Nieves PérezSolórzano. European Union Politics. Oxford University Press. Terceira Edição, 2010, p.32-47.

RAJARAM, P. K.; GRUNDY-WARR, C. In: RAJARAM, P.K.; GRUNDY-WARR, C. (Eds.).Boderscapes: hidden geographies and politics at territory's edge. Minneapolis: University of Minnesota Press, 2007, p. ix- $x$

RAE, H. State Identities and the Homogenization of Peoples. Cambridge: Cambridge University Press, 2002..

SALAZAR, K. C. El Papel de los Derechos Humanos en la Política Exterior de la Unión Europea: Un Modelo de Análises. Relaciones Internacioales, n.17, 2011, p.13-30. 
THE GUARDIAN. Berlusconi claims he will empty Italian island of Lampedusa of migrants. Roma, 2011, World. Disponível em: <http://www.theguardian.com/world/2011/mar/30/berlusconi-emptyisland-lampedusa-migrants>. Acesso em: 22 de nov. 2013.

WÆVER, O. Societal security: the concept. In: WÆVER, O. et al. Identity, Migration and the New Security Agenda in Europe. St. Martin's Press, New York, 1993, cap.2.

Securitization and Desecuritization. In: LIPSCHUTZ, Ronnie D. On Security. Columbia University Press, New York, 1998, p.46-86.

. European Security Identities. Journal of Common Market Studies, v34, n1, 1996, p.103-132.

WALKER, R.B.J. Inside/Outside: International Relations as Political Theory. Cambridge University Press, 1993, p.1-21. The Double Outsides of the Modern International.

Ephemera: Theory \& Politics in organization, v6, n1, 2006, p.5669. 